\title{
Efeitos neuroprotetores do Pomegranate no acidente vascular encefálico: Revisão Sistemática
}

\author{
Neuroprotective effects of Pomegranate in Stroke: Systematic Review
}

Stênio Karlos Alvim Fiorelli ${ }^{1,2,4}$, Rodrigo Ceciliano ${ }^{1}$, Luna Pereira ${ }^{1}$, Gabriel Duro ${ }^{1}$, Gabriel Amim Fiorelli ${ }^{4}$, Henrique Amim Fiorelli ${ }^{4}$, Mariana Zandoná2 ${ }^{2}$, Júlio C. Nunes ${ }^{2}$, Camille Feitoza ${ }^{2}$, Solange Miranda Junqueira Guertzenstein ${ }^{2,4}$, Vitor Hugo ${ }^{3}$, Silmar Teixeira $^{3}$, Adalgiza Mafra Moreno ${ }^{5}$, Valécia Carvalho ${ }^{3}$, Rossano Kepler Alvim Fiorelli ${ }^{2,4}$, Lucia Marques Vianna ${ }^{2}$; Marco Orsini ${ }^{4}$

1.Universidade Estácio de Sá. Disciplina de Clínica Cirúrgica (UNESA), Rio de Janeiro-RJ, Brasil.

2.Universidade Federal do Estado do Rio de Janeiro. Programa de pós-graduação em Neurologia/Neurociências, Laboratório de investigação em nutrição e doenças crônico-degenerativas (UNIRIO), Rio de Janeiro-RJ, Brasil.

3. Universidade Federal do Piauí. Laboratório de mapeamento e plasticidade do cérebro (UFPI), ParnaíbaPi, Brasil.

4Universidade Iguaçu - Rio de Janeiro - Brasil. Programa de Mapeamento Cerebral e Funcionalidade IPFI - UFPI.

5,Universidade Iguaçu, Rio de Janeiro-RJ, Brasil.

\begin{abstract}
Resumo
Introdução. O acidente vascular encefálico (AVE) representa a maior causa de incapacitação da população acima dos 50 anos. Visto sua importância epidemiológica como problema de saúde pública, pela magnitude de sua prevalência e incidência, estratégias preventivas devem ser adotadas, como o estudo de produtos para redução do número de casos e gravidade. O Pomegranato, fruta Romã (Punica granatum L.), rica em compostos fenólicos aos quais se atribuem ação neuroprotetora, pode se tornar um alimento funcional sendo um novo alvo terapêutico. Igualmente rica em agentes bioativos, como Resveratrol, pode também retardar as complicações do estresse oxidativo presente na neuroinflamação, presente na patogênese de doenças como o Alzheimer, Parkinson e AVE. Método. O presente estudo realizou uma revisão sistemática para eleger trabalhos que apresentem relevância frente à relação de neuroproteção do Pomegranato e o AVE. Resultados. Os trabalhos selecionados foram considerados como cumprindo os critérios de elegibilidade para inclusão no estudo. O resultado apresentou a seleção final de 19 artigos que atendiam a todos os critérios na seleção dos estudos e extração dos dados. A partir, da leitura completa dos artigos selecionados, podemos apresentar que há relação entre o consumo de Pomegranato e diminuição de espécies reativas de oxigênio (ROS) e inflamação resultante da isquemia focal. Conclusão. Este achado aponta que alimentos enriquecidos por polifenóis presente na romã, entre outras fontes de biodisponibilidade, pode vir a ser um novo alvo terapêutico além de diminuir a incidência de preditivos de risco relacionados ao AVE.
\end{abstract}

Unitermos. Acidente Vascular Encefálico; Pomegranate; Efeito Neuroprotetor

\footnotetext{
Abstract

Introduction. Stroke is the major cause of disability in the population over 50 years. Given its epidemiological importance as a public health problem, due to the magnitude of its prevalence and incidence, preventive strategies should be adopted, such as the study of products to reduce the number of cases and severity. Pomegranate, Pomegranate fruit (Punica granatum L.), rich in phenolic compounds to which neuroprotective action is attributed, can become a functional food and a new therapeutic target. Equally rich in bioactive agents, such as Resveratrol, can also delay the complications of oxidative stress present in neuroinflammation, present in the pathogenesis of diseases such as Alzheimer's, Parkinson's and stroke. Method. This study conducted a systematic review to elect papers that are relevant to the neuroprotective relationship of Pomegranate and stroke. Results. The selected papers were considered as meeting the eligibility criteria for inclusion in the study. The result presented the final selection of 19 articles that met all criteria in the
} 
selection of studies and data extraction. From the complete reading of the selected articles, we can show that there is a relationship between Pomegranate consumption and decreased reactive oxygen species (ROS) and inflammation resulting from focal ischemia. Conclusion. This finding points out that polyphenol-enriched foods present in pomegranate, among other sources of bioavailability, may become a new therapeutic target in addition to decreasing the incidence of stroke-related risk predictors.

Keywords. Stroke; Pomegranate; Neuroprotective Effect

Trabalho realizado na Universidade Estácio de Sá. Rio de Janeiro-RJ, Brasil.

Conflito de interesse: não

Recebido em: julho de 2017

Aceito em: 1/12/2017

Endereço para correspondência: Stênio KA Fiorelli, R. Mariz e Barros, 775. Maracanã. Rio de Janeiro-RJ, Brasil. CEP 20270-901. Email: skfiorelli@uol.com.br

\section{INTRODUÇÃO}

O acidente vascular encefálico (AVE) é uma desordem multifatorial heterogênea reconhecida pelo aparecimento súbito de sinais neurológicos diretamente relacionados aos locais da lesão no encéfalo, desencadeando o processo mórbido da patogênese ${ }^{1}$. É uma doença neurológica debilitante que aumenta a frequência com a idade; estimase que, em 2030, 23 milhões de pessoas desenvolveram a doença, resultando em 7,8 milhões de mortes ${ }^{2}$. Para pacientes, com faixa etária superior a 50 anos, seis meses após AVE, 26\% são dependentes de suas atividades diárias e $46 \%$ apresentam déficits cognitivos. Este quadro clínico tem demonstrado o enorme impacto global financeiro, tanto para os serviços de saúde quanto nas vidas de pacientes, familiares e outros cuidadores ${ }^{3}$.

Estudos epidemiológicos identificaram os principais preditores de risco para a ocorrência e recorrência da doença, entre estes são hipertensão, diabetes, fibrilação atrial, ataque isquêmico transitório, hipercolesterolemia, tabagismo e estenose carotídea; e além dos fatores de 
risco ambientais, o componente genético substancial tem como estimativas de $17 \%$ a $38 \%$ para o desenvolvimento de $A V E^{3,4}$. Dentre os fatores responsáveis a alta incidência, a transição demográfica com $\circ$ envelhecimento populacional tem grande relevância frente à etiologia da doença ${ }^{5-7}$. Apesar dos recentes avanços no tratamento agudo, a prevenção efetiva do AVE primário, por meio do controle, buscando hábitos saudáveis e reduzindo os fatores de risco, tem maior potencial para reduzir seus danos $^{8}$.

Por esta perspectiva, alternativas de tratamento e profilaxia a partir de estudos fitoquímicos para pacientes de AVE vêm sendo desenvolvidas e em especial o efeito do suco de Romã (Pomegranato, Punica granatum L.) vem ganhando destaque por apresentar proteção em ratos neonatos contra doença cerebral isquêmica por hipoxemia em ensaios experimentais ${ }^{9}$. Estudos ainda apontam o potencial da romã no emprego de seu extrato junto a ingredientes alimentares funcionais e nutracêuticos ${ }^{10}$. A romã é uma rica fonte de compostos bioativos com capacidade antioxidante. Nos últimos anos, estudos mostraram que esta fruta tem inúmeros benefícios para a saúde humana, o que aumentou o interesse em estudar suas propriedades terapêuticas ${ }^{11}$.

Esta revisão sistemática tem como objetivo realizar uma atualização da relação existente entre o Pomegranato e o AVE isquêmico. Incluindo aspectos neuprotetores da romã no AVE, efeito dos bioativos em modelos 
experimentais com animais, inclusão do extrato a alimentos, e novos estudos sobre a aplicação do Pomegranato para diminuir riscos de adquirir AVE. Assim, avaliamos trabalhos que apontam o Pomegranato atuando nas doenças cerebro-vasculares e resultando na neuroproteção, uma vez que os componentes que compõe este extrato apresentam interação com a resposta inflamatória e efeito antioxidante. Nosso estudo permite demonstrar que os estudos selecionados apresentam relevância e elegitividade para abordagem proposta, e assim, torna-se fator relevante para a neurociência na busca de elucidar o princípio de ação dos bioativos estudados como uma alternativa terapêutica e profilática no desenvolvimento da doença.

Realizamos um estudo que demonstra os aspectos de biodisponibilidade, fitoquímica, efeito dose-resposta e aplicações terapêuticas do Pomegranato, em especial para pacientes com AVE, além de novos estudos sobre o efeito neuroprotetor dos componentes extraídos dessa fruta, destacando os compostos fenólicos. Inicialmente, buscamos estruturar os principais acometimentos em pacientes com acidente vascular encefálico, relações neuroquímicas, neuroprotetores, imunofarmacologia e relacionado com 0 AVE. Desse modo, nossos achados fornecem um quadro atualizado para relação de AVE e o Pomegranate, apontando o estado da arte, limitações e direções futuras para pesquisas sobre tema. 


\section{MÉTODO}

Utilizamos o método PRISMA para a revisão sistemática, por meio de artigos em inglês e português sobre aspectos neuroprotetores do Pomegranato para prevenir $\mathrm{O} \mathrm{AVE}$, testes fitoquímicos em modelos experimentais com animais, e novos estudos sobre 0 potencial terapêutico e nutracêutico dos agentes bioativos no extrato da fruta para a doença. Incluímos em nosso estudo: revisões, meta-análise, relatos de casos e trabalhos originais. Nenhum status de publicação ou restrição de data de publicação foi imposto. Utilizamos como critérios de exclusão: (a) dissertações, (b) revisões de livros, (c) trabalhos de conferência ou editoriais. Os trabalhos considerados relevantes foram analisados e incluídos no estudo.

\section{Fontes de informação}

As buscas on-line nas bases de dados Scielo, Pubmed/Medline e ISI Web of Knowledge (2007-2017), inicialmente foram realizadas em maio de 2017 e repetidas em setembro de 2017 usando termos e associações relevantes: (e.g. [Efeito Neuroprotetor e Pomegranate], [Compostos fenólicos e AVE], [Resveratrol e AVE], [Pomegranate e AVE]); todos indexados no MESH / Pubmed. As pesquisas ocorreram em dois momentos, à primeira foi destinada aos aspectos de neuroproteção e biodisponibilidade do Pomegranado para que pudesse permitir o entendimento dos mecanismos de ação desses 
alimentos a partir da sua composição química frente aos aspectos de patogênese do AVE isquêmico, ao passo que no segundo momento, focamos nos compostos fenólicos, Resveratrol e por fim associação direta entre os principais grupos de interesse, o Pomegranate e novos estudos relacionados à profilaxia e terapêutica voltada para pacientes com AVE. Para tal, examinamos resumos para referências direcionadas à nossa pesquisa, além de verificar se o estudo é relevante ao nosso levantamento, então o artigo completo foi obtido.

\section{Seleção de estudo}

Inicialmente, os documentos recuperados da base de dados foram comparados para remover registros duplicados. Os documentos foram selecionados para elegibilidade com base em seu título e resumo e, quando necessário, a publicação de texto completo foi revisada. Tipos de modalidades: foram incluídos estudos que investigaram a conectividade neuroprotetora usando relação entre efeito do Pomegranate e o AVE. Estudos de conectividade neuroquímica baseados em aspectos fitoquímicos e farmacocinéticos aplicados ao AVE também foram incluídos.

Em suma:

Projeto de estudo: Estudos experimentais, metaanálises, documentos originais e projetos de revisão foram incluídos. 
População: população de estudo composta de indivíduos saudáveis ou indivíduos com AVE (por exemplo, adultos jovens, de meia-idade e idosos). Além de cobaias não humanas.

Intervenção: as intervenções profiláticas foram definidas como qualquer relação entre o potencial de ação do composto extraído do Pomegranate e a fisiopatologia cerebral associada ao quadro clínico de $A V E$, a partir do efeito neuroprotetor do fruto romã.

Resultado: a medida de resultado primária foi o efeito protetor do extrato do Pomegranate para o desenvolvimento do $A V E$, diminuindo assim o risco de desenvolver a doença.

A pesquisa de banco de dados identificou 193 publicações únicas para a combinação dos descritores de estudo. Os documentos foram selecionados para elegibilidade com base em seu título e resumo e, quando necessário, a publicação de texto completo foi revista. Estes documentos foram avaliados quanto à elegibilidade com base em título e resumo; 41 foram classificados como critérios de elegibilidade para reunião. A próxima etapa do processo de cobrança envolveu o rastreio de texto completo dos documentos potencialmente relevantes; dos quais posteriormente foram considerados como cumprindo os critérios de elegibilidade. Consequentemente, no total, os estudos 19 foram incluídos na revisão (Figura 1). 
Figura 1. Processo de seleção dos artigos selecionados para a sistematização.

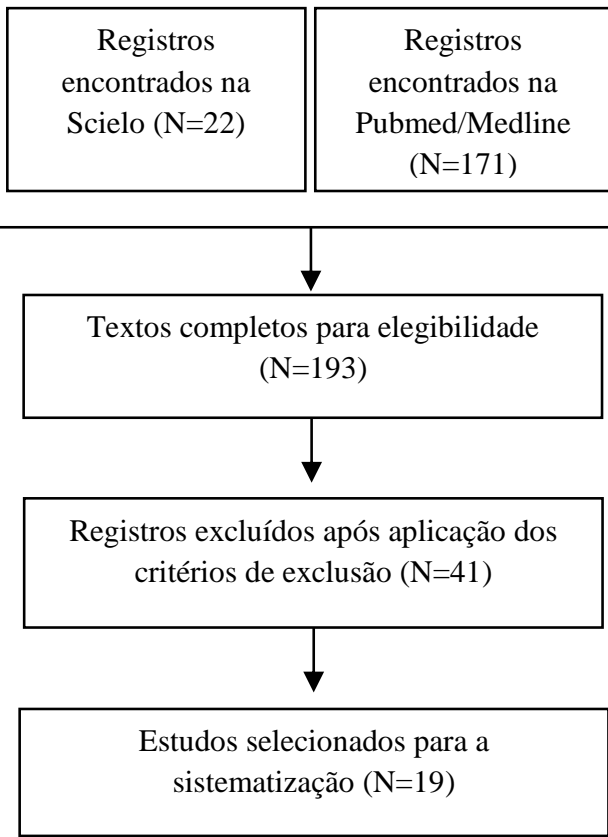

\section{Seleção de estudo e extração de dados}

Três revisores (FA, FC, OM) leram independentemente os títulos e/ou resumos dos documentos identificados e eliminaram estudos irrelevantes. Os estudos considerados elegíveis para inclusão foram lidos na íntegra e sua adequação para inclusão foi determinada de forma independente. Os desentendimentos foram geridos por consenso. No entanto, se isso não foi bem-sucedido, o consenso foi procurado por um quarto crítico (ST).

Os dados foram extraídos com base no design e configuração do estudo. Alguns autores foram contatados para fornecer informações suplementares quando dados insuficientes foram fornecidos no estudo. Os autores de dois estudos foram contatados para obter mais 
informações, tendo lido seus títulos e resumos. Dois responderam; uma vez que baseia a revisão da literatura cumprida os critérios de inclusão.

\section{RESULTADOS}

A análise do conteúdo dos artigos foi realizada por meio do tipo de estudo, protocolo aplicado, resultados principais e aplicabilidade para terapêutica e profilaxia, reportados na Tabela 1 . Os resultados contam com cinco estudos experimentais de modelo animal aplicado em ratos, dois estudos com cultura celular e 12 revisões, selecionados por estarem relacionados com os efeitos neuroprotetores e antioxidantes do Pomegranato e à fisiopatologia do AVE.

O estudo prospectivo se baseou na investigação fitoquímica do Pomegranato e no seu potencial de ação dos bioativos e apontou que há presença de neuroproteção a partir da administração do extrato de Pomegranato, da Romã, ou do polifenol Resveratrol, entre outras fontes de biodisponibilidade, testados por características antioxidantes, em lesão isquêmica induzem nos ratos e nos danos celulares, observados nas culturas celulares testadas, e com indicações futuras para uso terapêutico em casos de AVE. Este estudo observou relatos que apoiam estratégias alimentares para a prevenção de doenças neurodegenerativas, como a suplementação dietética rica em compostos fenólicos e desenvolvimento de alimentos nutracêuticos. 
Diante dos resultados, observamos que 0 Pomegranato apresenta alto potencial terapêutico para futuras intervenções na profilaxia e tratamento de AVE, com possibilidades de implementação de bioativos resultantes do extrato do fruto Romã, entre outros alimentos, na formulação de alimentos nutracêuticos ou aplicação do Resveratrol em casos de isquemia cerebral aguda, apresentando efeito redutor dos danos nas primeiras 24 horas.

\section{DISCUSSÃO}

Este estudo analisou trabalhos experimentais e revisões acerca do efeito neuroprotetor do Pomegranato. Os resultados observados apontaram uma relação de causa subjacente entre o estresse oxidativo e o dano cerebral e disfunção neural após isquemia vascular encefálica. A patogênese do AVE isquêmico revela correlação com o aumento de espécies reativas de oxigênio (ROS) e resposta inflamatória resultante e estes achados estão relacionados com efeitos positivos encontrados nos modelos experimentais observados na literatura ${ }^{14,18-20,23,24}$. A produção de ROS após lesão está associada à ativação das enzimas dependentes de $\mathrm{Ca}^{2+}$ e alterações das vias de sinalização que levam à disfunção mitocondrial e a apoptose neuronal ${ }^{12,18,26}$. 
Tabela 1: Características dos estudos sobre os efeitos neuroprotetores do Pomegranato e AVE.

\begin{tabular}{|c|c|c|c|}
\hline Author & Methods & Protocol & $\begin{array}{c}\text { Results } \\
\end{array}$ \\
\hline West $2007^{9}$ & $\begin{array}{l}\text { Estudo experimental, } \\
\text { com ratos. }\end{array}$ & $\begin{array}{lrr}\text { Indução de } & \text { isquemia } \\
\text { cerebral em ratos } \\
\text { neonatos e } \\
\text { tratamento } \\
\text { Resveratrol. De acordo } \\
\text { com as diretrizes NIH. } \\
\end{array}$ & $\begin{array}{l}\text { O estudo demonstrou } \\
\text { fornecer neuroproteção } \\
\text { em modelos animais } \\
\text { com lesão cerebral } \\
\text { neonatal. }\end{array}$ \\
\hline Raval $2008^{14}$ & Revisão & $\begin{array}{l}\text { Levantamento } \\
\text { estudos relatam os } \\
\text { efeitos benéficos do } \\
\text { resveratrol: } \\
\text { antioxidação, eliminação } \\
\text { de radicais livres e } \\
\text { modulação } \\
\text { homeostase de energia } \\
\text { neuronal e receptores } \\
\text { glutamatérgicos / canais } \\
\text { iónicos. }\end{array}$ & $\begin{array}{l}\text { O estudo examina os } \\
\text { caminhos comuns de } \\
\text { sinalização, r alvos } \\
\text { celulares do resveratrol } \\
\text { e neuroproteção } \\
\text { induzida por pré- } \\
\text { condicionamento } \\
\text { isquêmico cerebral. }\end{array}$ \\
\hline Ghosh $2009^{15}$ & Revisão & $\begin{array}{l}\text { Levantamento de } \\
\text { estudos epidemiológicos } \\
\text { que descrevem sugerem } \\
\text { que o consumo regular } \\
\text { de alimentos e bebidas } \\
\text { ricos em flavonoides } \\
\text { está associado a uma } \\
\text { redução no risco de } \\
\text { várias patologias que } \\
\text { variam de hipertensão a } \\
\text { doença coronária, } \\
\text { acidente vascular } \\
\text { cerebral e demência. }\end{array}$ & $\begin{array}{l}\text { O estudo aponta o } \\
\text { caminho para o } \\
\text { desenvolvimento de } \\
\text { novos tipos de alimentos } \\
\text { funcionais voltados para } \\
\text { a saúde do cérebro } \\
\text { através da melhoria da } \\
\text { saúde vascular. }\end{array}$ \\
\hline Albani $2010^{16}$ & Revisão & $\begin{array}{lr}\text { Levantamento } & \text { de } \\
\text { estudos } & \text { que } \\
\text { demonstram } & \text { as } \\
\text { propriedades } & \\
\text { neuroprotetoras } & \text { do } \\
\text { resveratrol, exibindo } \\
\text { ativação de enzimas } \\
\text { com atividade de } \\
\text { desacetilase, envolvidas } \\
\text { em vários processos } \\
\text { fisiológicos } \\
\text { patológicos, } \\
\text { neurodegeneração. }\end{array}$ & $\begin{array}{l}\text { O estudo trás os } \\
\text { resultados } \\
\text { experimentais in vitro e } \\
\text { in vivo que destacam o } \\
\text { possível papel do } \\
\text { resveratrol } \\
\text { biofator } \\
\text { neuroproteção, } \\
\text { particular para DA. }\end{array}$ \\
\hline
\end{tabular}

Extrato hidroalcoólico de polpa (PHE); Extrato aquoso de polpa (PAE); Suco de romã (PJ); Rotenona (Sigma-Aldrich) (ROT);

Veiculo - água com açúcar - (VHE); Espécies reativas de oxigênio (ROS); Acidente vascular encefálico (AVE); Doença de

Alzheimer (DA). 
Tabela 1 (cont.): Características dos estudos sobre os efeitos neuroprotetores do Pomegranato e AVE.

\begin{tabular}{|c|c|c|c|}
\hline Shin $2010^{17}$ & $\begin{array}{l}\text { Estudo experimental, } \\
\text { com ratos. }\end{array}$ & $\begin{array}{l}\text { Foi realizada uma } \\
\text { indução isquêmica com } \\
\text { separação aleatória em } \\
\text { grupos de controle e } \\
\text { tratamento (VHE e } \\
\text { RESV) para posterior } \\
\text { administração de } \\
\text { Resveratrol não superior } \\
\text { a } 0,3 \mathrm{~g} \mathrm{/} \mathrm{kg.} \mathrm{Com} \\
\text { analises por RT-PCR, } \\
\text { Western Blot, coloração } \\
\text { por Imunofluorescência } \\
\text { e Quantificação da } \\
\text { produção ROS. }\end{array}$ & 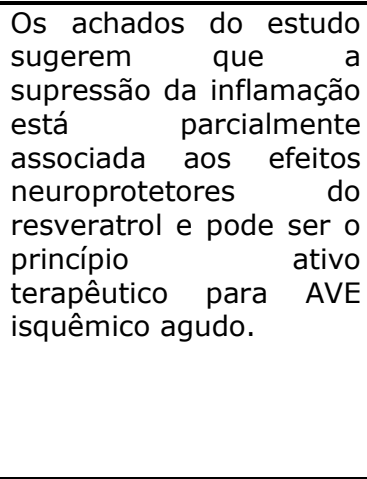 \\
\hline Sun $2010^{18}$ & Revisão & $\begin{array}{l}\text { Levantamento } \\
\text { estudos que descrevem } \\
\text { os mecanismos } \\
\text { oxidativos associados ao } \\
\text { AVE, DA e DP e, } \\
\text { posteriormente, } \\
\text { colocamos ênfase em } \\
\text { estudos recentes } \\
\text { envolvendo efeitos } \\
\text { neuroprotetores do } \\
\text { resveratrol, polifenólico } \\
\text { composto pol } \\
\text { derivado de uvas e } \\
\text { vinho tinto. }\end{array}$ & 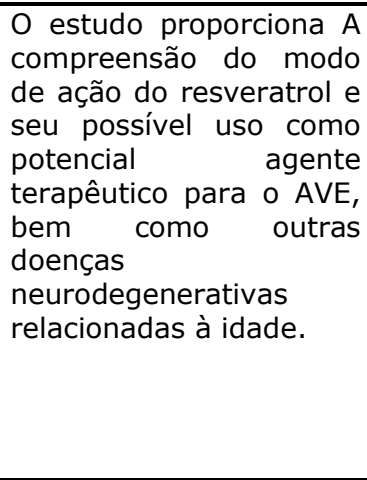 \\
\hline Forouzanfar $2013^{19}$ & $\begin{array}{l}\text { Estudo experimental, } \\
\text { com cultura celular. }\end{array}$ & $\begin{array}{l}\text { Três grupos de células } \\
\text { PC12 (PHE, PAE e PJ) } \\
\text { foram cultivados e } \\
\text { induzidos apoptose. }\end{array}$ & $\begin{array}{l}\text { O estudo demonstrou } \\
\text { que o pré-tratamento o } \\
\text { PJ tem potencial } \\
\text { neuroprotetor. }\end{array}$ \\
\hline Singh $2013^{20}$ & Revisão & $\begin{array}{lr}\text { Levantamento } & \text { de } \\
\text { estudos que } \\
\text { demonstram as } \\
\text { propriedades } \\
\text { neuroprotetoras e os } \\
\text { mecanismos de ação do } \\
\text { Resveratrol em modelos } \\
\text { experimentais em in } \\
\text { vitro e in vivo, e eficácia } \\
\text { da droga em achados } \\
\text { pré-clínicos e clínicos. }\end{array}$ & $\begin{array}{l}\text { O estudo relata que o } \\
\text { resveratrol } \\
\text { potencial de dem } \\
\text { terapêutico e é umão } \\
\text { promessa para o } \\
\text { tratamento de doenças } \\
\text { neurodegenerativas. }\end{array}$ \\
\hline Rodrigo $2013^{21}$ & Revisão & $\begin{array}{lr}\text { Levantamento } & \text { de } \\
\text { estudos que revisaram } \\
\text { as evidências do } \\
\text { estresse oxidativo, das } \\
\text { estratégias r com } \\
\text { antioxidantes e ra } \\
\text { fisiopatologia do } \\
\text { acidenterascular } \\
\text { cerebral isquêmico. }\end{array}$ & $\begin{array}{l}\text { O estudo relata os } \\
\text { mecanismos envolvidos } \\
\text { na geração de ROS, o } \\
\text { papel do estresse } \\
\text { oxidativo na patogênese } \\
\text { do AVE isquêmico e as } \\
\text { estratégias terapêuticas } \\
\text { novas a serem testadas } \\
\text { para reduzir o dano } \\
\text { cerebral relacionado à } \\
\text { isquemia e à reperfusão. }\end{array}$ \\
\hline Tapias $2014^{22}$ & $\begin{array}{l}\text { Estudo experimental, } \\
\text { com rato. }\end{array}$ & 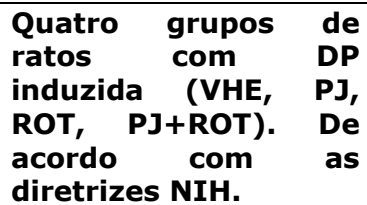 & $\begin{array}{l}\text { Os resultados } \\
\text { forneceram evidências } \\
\text { novas e fortes para um } \\
\text { efeito pró-oxidante de PJ } \\
\text { em um modelo de DP. }\end{array}$ \\
\hline
\end{tabular}

Extrato hidroalcoólico de polpa (PHE); Extrato aquoso de polpa (PAE); Suco de romã (PJ); Rotenona (Sigma-Aldrich) (ROT); Veiculo - água com açúcar - (VHE); Espécies reativas de oxigênio (ROS); Acidente vascular encefálico (AVE); Doença de Alzheimer (DA). 
Tabela 1 (cont.): Características dos estudos sobre os efeitos neuroprotetores do Pomegranato e AVE.

\begin{tabular}{|c|c|c|c|}
\hline Nabavi $2014^{23}$ & Revisão & $\begin{array}{l}\text { Levantamento } \\
\text { estudos } \\
\text { demonstram os que o } \\
\text { estresse oxidativo } \\
\text { desempenha um papel } \\
\text { importante na } \\
\text { patogênese do AVC e, } \\
\text { portanto, a terapia } \\
\text { antioxidante pode ser } \\
\text { usada como uma nova } \\
\text { estratégia terapêutica. }\end{array}$ & $\begin{array}{l}\text { O estudo demonstra o } \\
\text { papel benéfico do } \\
\text { resveratrol no AVE } \\
\text { isquêmico. Além de } \\
\text { fornecer informações } \\
\text { sobre química, } \\
\text { biodisponibilidade, bem } \\
\text { como os impactos } \\
\text { clínicos do resveratrol. }\end{array}$ \\
\hline Lopez $2015^{24}$ & Revisão & $\begin{array}{lr}\text { Levantamento } & \text { de } \\
\text { estudos } & \text { que } \\
\text { demonstram os } & \text { os } \\
\text { benefícios induzidos por } & \text { são } \\
\text { resveratrol } & \text { modulados por múltiplos } \\
\text { caminhos sinérgicos que } \\
\text { controlam o estresse } \\
\text { oxidativo, a inflamação } \\
\text { e a morte celular. }\end{array}$ & $\begin{array}{l}\text { O estudo relata estudos } \\
\text { in vivo e in vitro } \\
\text { sugerindo que o } \\
\text { resveratrol pode induzir } \\
\text { um estado } \\
\text { neuroprotetivo quando } \\
\text { administrado no estágio } \\
\text { agudo, ou antes, de } \\
\text { lesão experimental ao } \\
\text { SNC. Foco nas vias } \\
\text { moleculares } \\
\text { responsáveis } \\
\text { neuroproteção. pela }\end{array}$ \\
\hline Bastianetto $2015^{25}$ & Revisão & $\begin{array}{lr}\text { Levantamento } & \text { de } \\
\text { estudos } & \text { que } \\
\text { demonstraram } & \text { as } \\
\text { descobertas } & \text { mais } \\
\text { recentes sobre os } \\
\text { mecanismos de ação } \\
\text { envolvidos nos efeitos } \\
\text { protetores do } \\
\text { Resveratrol e discute } \\
\text { seus possíveis papéis na } \\
\text { prevenção de vários } \\
\text { distúrbios neurológicos } \\
\text { relacionados à idade. }\end{array}$ & $\begin{array}{l}\text { O estudo relata que o } \\
\text { resveratrol apresentou } \\
\text { atividades pleiotrópicas, } \\
\text { incluindo efeitos } \\
\text { antioxidantes e anti- } \\
\text { inflamatórios, bem como } \\
\text { uma ação inibitória, que } \\
\text { sustenta que é um dos } \\
\text { compostos mais } \\
\text { promissores para o } \\
\text { desenvolvimento de } \\
\text { terapias para DA. }\end{array}$ \\
\hline Sun $2016^{26}$ & $\begin{array}{l}\text { Estudo Experimental, } \\
\text { cultura celular. }\end{array}$ & $\begin{array}{l}\text { Três grupos de células } \\
\mathrm{N} 2 \mathrm{a} \text { (grupo normal, } \\
\text { grupo modelo e grupo } \\
\text { controle). Foi feito uma } \\
\text { avaliação do extrato de } \\
\text { própolis quanto ao dano } \\
\text { celular induzido por } \\
\text { privação de Glicose e } \\
\mathrm{O}_{2} \text {. }\end{array}$ & $\begin{array}{l}\text { O efeito antioxidante do } \\
\text { própolis pode ser } \\
\text { aplicado } \\
\text { suplementos } \\
\text { alimentares diários e } \\
\text { pode beneficiar } \\
\text { pacientes com AVE. }\end{array}$ \\
\hline Wan $2016^{27}$ & $\begin{array}{l}\text { Estudo experimental, } \\
\text { com ratos. }\end{array}$ & $\begin{array}{l}\text { Os níveis de ATP em } \\
\text { tecidos cerebrais de } \\
\text { ratos foram detectados } \\
\text { por HPLC. SIRT1 e a P- } \\
\text { AMPK foram avaliadas } \\
\text { por Western Blot. Os } \\
\text { níveis de PDEs e CAMP } \\
\text { foram quantificados por } \\
\text { RT-PCR e ELISA, } \\
\text { respectivamente. De } \\
\text { acordo com as diretrizes } \\
\text { NIH. }\end{array}$ & $\begin{array}{l}\text { O resveratrol fornece } \\
\text { neuroproteção inibindo } \\
\text { fosfodiesterases } \\
\text { regulando a via cAMP / } \\
\text { AMPK / SIRT1 após o } \\
\text { acidente vascular } \\
\text { cerebral em ratos. }\end{array}$ \\
\hline
\end{tabular}


Tabela 1 (cont.): Características dos estudos sobre os efeitos neuroprotetores do Pomegranato e AVE.

\begin{tabular}{|c|c|c|c|}
\hline Dias $2016^{28}$ & Revisão & $\begin{array}{l}\text { Levantamento de } \\
\text { estudos que } \\
\text { demonstram evidências } \\
\text { recentes que implicam o } \\
\text { resveratrol na regulação } \\
\text { da plasticidade neural } \\
\text { do hipocampo e os } \\
\text { efeitos em vários } \\
\text { transtornos e doenças } \\
\text { nesta importante } \\
\text { estrutura cerebral. }\end{array}$ & $\begin{array}{l}\text { O estudo mostra que o } \\
\text { resveratrol pode } \\
\text { melhorar a cognição e o } \\
\text { humor e aumentar a } \\
\text { plasticidade } \\
\text { hipocampo e AHN. }\end{array}$ \\
\hline Li $2016^{29}$ & $\begin{array}{l}\text { Estudo experimental, } \\
\text { com ratos. }\end{array}$ & $\begin{array}{l}\text { Foi realizado o Morris } \\
\text { Water Maze Test foi } \\
\text { usado para avaliar a } \\
\text { aprendizagem e a } \\
\text { memória, o registro } \\
\text { eletrofisiológico foi } \\
\text { utilizado para detectar a } \\
\text { plasticidade sináptica, a } \\
\text { coloração de Golgi foi } \\
\text { utilizada para examinar } \\
\text { a alteração das } \\
\text { terminações dendríticas, } \\
\text { o Western Blot foi usada } \\
\text { para detectar os níveis } \\
\text { de proteínas. De acordo } \\
\text { com as diretrizes } \mathrm{NIH} \text {. }\end{array}$ & $\begin{array}{l}\text { O estudo relatou que o } \\
\text { pré-tratamento com } \\
\text { resveratrol efetivamente } \\
\text { restabelece r sináptica } \\
\text { plasticidade } \\
\text { em ratos } \mathrm{CCH} \text {, } \\
\text { funcionais e estruturais. } \\
\text { Também descobrimos } \\
\text { que a ativação PKA- } \\
\text { CREB pode ser } \\
\text { importante } \\
\text { neuroproteção mediada } \\
\text { pelo resveratrol no } \\
\text { modelo } \mathrm{CCH} \text {. }\end{array}$ \\
\hline
\end{tabular}

A descoberta e o desenvolvimento de produtos naturais com potenciais propriedades antioxidantes, antiinflamatórias e antiapoptóticas estão sendo uma das abordagens mais promissoras na busca do tratamento de muitas doenças neurodegenerativas, incluindo acidente vascular encefálico isquêmico ${ }^{19}$. A suplementação dietética com alimentos ricos em polifenóis demonstrou fornecer neuroproteção em modelos animais de isquemia cerebral focal por evitar a agregação plaquetária e inibem o estresse oxidativo, e assim diminuindo os preditivos de risco à patogênese por direcionar a saúde do cérebro através da melhoria da saúde vascular ${ }^{15,17,21}$. 
Um caminho para melhor entendimento dos mecanismos envolvidos nos efeitos benéficos relatados sobre os bioativos à saúde através de propriedades antioxidantes e supressão de vias inflamatórias pode estar correlacionada a outras vias de regulação como a ativação da via das sirtuínas. Em particular a SIRT-1, uma das enzimas desacetilase de proteína humana da família das sirtuínas, que promove sobrevida celular por mecanismos como a regulação negativa de supressores de tumores p53 e assim ação antiapoptóticas ${ }^{9,27}$. A modulação desses caminhos pode fornecer um meio para proteger o cérebro dos danos causados por uma lesão isquêmica podendo originar novos alvos de estudo para o tratamento de distúrbios neurológicos ${ }^{25,29}$.

Quanto ao uso de Resveratrol, polifenol presente no Pomegranato, este inibe as moléculas pró-inflamatórias conhecidas como ciclooxigenases, particularmente a ciclooxigenase-1 (COX-1), uma enzima envolvida na produção de moléculas pró-inflamatórias conhecidas como citocinas. E este efeito foi associado à sua capacidade de reduzir a expressão de ciclooxigenase-2 (COX-2) e o fator de necrose tumoral a (TNFa) na substância nigra 25,28,29. O estudo também demonstrou que achados recentes em ensaios que utilizaram o Resveratrol, além das defesas antioxidantes, houve um aumentando dos níveis de glutationa, diminuição das citocinas no hipocampo de ratos e redução no consumo de energia, já que há estudos que demonstram o aumento do consumo de ATP durante o 
processo de lesão focal, um processo que pode explicar sua ação protetora contra a toxicidade associada à neuroinflamação e produção de ROS sendo relevante para o desenvolvimento de neurodegenerativas doenças ${ }^{27,29}$.

O mecanismo de neuroproteção do Resveratrol também apresentou efeito positivo em modelos experimentais tanto com animais quanto em culturas celulares para outras doenças neurodegenerativas, entre elas, Doença de Parkinson e Doença de Alzheimer ${ }^{16,22,25}$. Estudos recentes tentaram ainda correlacionar os efeitos observados a uma futura utilização profilática do bioativo e apontaram que o Resveratrol também melhorou a cognição, o humor e aumentou a plasticidade sináptica no modelo animal $^{28,29}$. Por fim, estudos realizaram uma análise com relação à comparação de modelos experimentais in vitro e in vivo e apontaram discrepância entre achados relatados em ensaios clínicos, fortalecendo a necessidade de comparações entre protocolos dose-resposta e visando recomendações para futuras aplicações terapêuticas em pacientes de AVE isquêmico ${ }^{13,16}$.

Portanto, essa multiplicidade de fatores representa uma série de desafios para pesquisadores que buscam princípios para melhor compreender a relação causal e possíveis intervenções para o AVE. A suplementação dietética e a relação de princípios bioativos estudados recentemente, em especial o extrato da Romã e o Resveratrol, podem fornecer novas informações sobre a neuroproteção e promoção terapêutica. Limitações 
envolvidas nas metodologias analisadas e tipos de ensaios experimentais para possíveis adaptações para ensaios clínicos ainda são um desafio para futuras adaptações em ensaios clínicos.

Há limitações para nosso estudo. Em termos de estratégia de pesquisa e coleta de dados, optamos por avaliar apenas os estudos que encontramos através do banco de dados ISI Web of Science, PubMed e Scielo, com descritores indexados no MeSH e DeCS e nos idiomas inglês e português, podendo ter limitado o número final de estudos selecionados e revisados. Houve a preocupação após a leitura dos textos completos e avaliado a elegitividade dos estudos finais quanto à confiabilidade e viabilidade das condições de aplicabilidade nos modelos experimentais, bem como a sua potencial subjetividade na avaliação neurofuncional dos modelos animais e dos danos resultantes nas culturas celulares após protocolos aplicados e resultados, selecionando estudos com maior homogeneidade experimental e controle da amostra, para evitar estimativas tendenciosas da eficácia da intervenção.

\section{CONCLUSÃO}

A revisão sistemática realizou um levantamento bibliográfico dos principais estudos que apontam correlação entre o efeito neuroprotetor do extrato do Pomegranate, o Resveratrol e a isquemia cerebral após lesão focal e possível ação profilática quanto à alimentação rica com os 
principais bioativos relacionados. Os achados apontam uma relação de neuroproteção e efeito antioxidante na administração do extrado do Pomegranate, do fruto Romã, entre outras biodisponibilidades, por atuarem na supressão anti-inflamatória, ativação das SIRT-1 e diminuição das taxas de ROS produzidos após lesão isquêmica cerebral. Portanto, a implementação de novas intervenções terapêuticas a partir de estudos fitoquímicos e experimentais do princípio bioativo do Pomegranato trazem novos caminhos frente à patogênese do AVE.

\section{REFERÊNCIAS}

1.Favate AS, Younger DS. Epidemiology of Ischemic Stroke. Neurologic Clinics 2016;34:967-80.

https://doi.org/10.1016/j.ncl.2016.06.013

2.Ibrahim-Verbaas CA, Fornage M, Bis JC, Choi SH, Psaty BM, Meigs $J B$, et al. Predicting stroke through genetic risk functions: The CHARGE risk score Project. Stroke 2014;45:403-12. https://doi.org/10.1161/STROKEAHA.113.003044

3.Tsivgoulis G, Psaltopoulou T, Wadley VG, Alexandrov AV, Howard G, Frederick $W$, et al. Adherence to a Mediterranean diet and prediction of incident stroke. Stroke 2015;46:780-5.

https://doi.org/10.1161/STROKEAHA.114.007894

4.Toni D, Di Angelantonio E, Di Mascio MT, Vinisko R, Bath PM, PRoFESS Study Group. Types of stroke recurrence in patients with ischemic stroke: a substudy from the PRoFESS trial. Inter J Stroke 2014;9:873-8. https://doi.org/10.1111/ijs.12150

5.Lavados PM, Hennis AJ, Fernandes JG, Medina MT, Legetic B, Hoppe $A$, et al. Stroke epidemiology, prevention, and management strategies at a regional level: Latin America and the Caribbean. Lancet Neurol 2007;6:362-72. https://doi.org/10.1016/S14744422(07)70003-0

6. Wang G, Joo H, Tong X, George MG. Hospital Costs Associated With Atrial Fibrillation for Patients With Ischemic Stroke Aged 18-64 Years in the United States. Stroke 2015;46:1314-20.

https://doi.org/10.1161/STROKEAHA.114.008563

7.World Health Organization (endereço na internet). Stepwise approach to stroke surveillance. Overview and Manual (version2.0). 
Noncommunicable Diseases and Mental Health. Geneva: World Health Organization 2015 (citado em 2015). Disponível em: http://www.who.int/entity/ncd surveilance/steps/en

8. Meschia JF, Bushnell C, Boden-Albala B, Braun LT, Bravata $D$, Chaturvedi $S$, et al. Guidelines for the Primary Prevention of Stroke. Stroke 2014;45:3754-832.

https://doi.org/10.1161/STR.0000000000000046

9. West T, Atzeva M, Holtzman DM. Pomegranate polyphenols and resveratrol protect the neonatal brain against hypoxic-ischemic injury. Dev Neurosci 2007;29:363-72.

https://doi.org/10.1159/000105477

10.Danesi F, Kroon PA, Saha S, de Biase D, D'Antuono LF, Bordoni A. Mixed pro-and anti-oxidative effects of pomegranate polyphenols in cultured cells. Int J Mol Sci 2014;5:19458-71.

https://doi.org/10.3390/ijms151119458

11. Morzelle MC, Ssalgado JM, Telles M, Mourelle D, Bachiega P, Buck HS, et al. Neuroprotective Effects of Pomegranate Peel Extract after Chronic Infusion with Amyloid- $\beta$ Peptide in Mice. PLoS One 2016;11:e0166123. https://doi.org/10.1371/journal.pone.0166123

12.Sun AY, Wang Q, Simonyi A, Sun GY. Botanical Phenolics and Brain Health. Neuromolecular Med 2008;10:259-74.

https://doi.org/10.1007/s12017-008-8052-z

13.Cherubini A, Ruggiero C, Morand C, Lattanzio F, Dell'Aquila G, Zuliani $G$, et al. Dietary antioxidants as potential pharmacological agents for ischemic stroke. Curr Med Chem 2008;15:1236-48. https://doi.org/10.2174/092986708784310431

14. Raval AP, Lin HW, Dave KR, Defazio RA, Della MD, Kim EJ, et al. Resveratrol and ischemic preconditioning in the brain. Curr Med Chem 2008;15:1545-51. https://doi.org/10.2174/092986708784638861

15.Ghosh D, Scheepens A. Vascular action of polyphenols. Mol Nutr Food Res 2009;53:322-31. https://doi.org/10.1002/mnfr.200800182 16.Albani D, Polito L, Signorini A, Forloni G. Neuroprotective properties of resveratrol in different neurodegenerative disorders. Biofactors 2010;36:370-6. https://doi.org/10.1002/biof.118

17.Shin JA, Lee H, Lim YK, Koh Y, Choi JH, Park EM. Therapeutic effects of resveratrol during acute periods following experimental ischemic stroke. J Neuroimmunol 2010;227:93-100. https://doi.org/10.1016/j.jneuroim.2010.06.017

18.Sun AY, Wang Q, Simonyi A, Sun GY. Resveratrol as a Therapeutic Agent for Neurodegenerative Diseases. Mol Neurobiol 2010;41:37583. https://doi.org/10.1007/s12035-010-8111-y

19.Forouzanfar F, Afkhami Goli A, Asadpour E, Ghorbani A, Sadeghnia HR. Protective Effect of Punica granatum L. against Serum/Glucose Deprivation-Induced PC12 Cells Injury. Evid Based Complement Alternat Med 2013;2013:716730.

https://doi.org/10.1155/2013/716730

20.Singh N, Agrawal M, Doré S. Neuroprotective Properties and Mechanisms of Resveratrol in in Vitro and in Vivo Experimental 
Cerebral Stroke Models. ACS Chem Neurosci 2013;4:1151-62. https://doi.org/10.1021/cn400094w

21.Rodrigo R, Fernandez-Gajardo R, Gutierrez R, Matamala JM, Carrassco R, Miranda-Merchak A, et al. Drug Targets Oxidative Stress and Pathophysiology of Ischemic Stroke: Novel Therapeutic Opportunities. CNS Neurol Disord Drug Targets 2013;12:698-714. https://doi.org/10.2174/1871527311312050015

22.Tapias V, Cannonc J, Greenamyre T. Pomegranate juice exacerbates oxidative stress and nigrostriatal degeneration in Parkinson's disease. Neurobiol Aging 2014;35:1162-76. https://doi.org/10.1016/j. neurobiolaging.2013.10.077

23. Nabavi SF, Li H, Daglia M, Nabavi SM. Resveratrol and stroke: from chemistry to medicine. Curr Neurovasc Res 2014;11:390-7. https://doi.org/10.2174/1567202611666140912114833

24.Lopez MS, Dempsey RJ, Vemuganti R. Resveratrol neuroprotection in stroke and traumatic CNS injury. Neurochem Inter 2015;89:7582. https://doi.org/10.1016/j.neuint.2015.08.009

25. Bastianetto S, Menarda C, Quiron R. Neuroprotective action of resveratrol. Biochim Biophys Acta 2015;1852:1195-201. https://doi.org/10.1016/j.bbadis.2014.09.011

26.Sun L, Xu X, Hwang H, Wang X, Su K, Chen YS. Dichloromethane extracts of propolis protect cell from oxygen-glucose deprivationinduced oxidative stress via reducing apoptosis. Food Nutr Res 2016;60:30081. https://doi.org/10.3402/fnr.v60.30081

27.Wan D, Zhou Y, Wang K, Hou Y, Hou R, Ye X. Resveratrol provides neuroprotection by inhibiting phosphodiesterases and regulating the CAMP/AMPK/SIRT1 pathway after stroke in rats. Brain Res Bull 2016;121:255-62.

https://doi.org/10.1016/j.brainresbull.2016.02.011

28. Dias GP, Cocks G, Nascimento Bevilaqua MC, Nardi AE, Thuret S. Resveratrol: a potential hippocampal plasticity enhancer. Oxid Med Cell Longev 2016;2016:9651236.

https://doi.org/10.1155/2016/9651236

29.Li H, Wang J, Wang P, Rao Y, Chen L. Resveratrol Reverses the Synaptic Plasticity Deficits in a Chronic Cerebral Hypoperfusion Rat Model. J Stroke and Cerebrovasc Dis 2016;25:122-8.

https://doi.org/10.1016/j.jstrokecerebrovasdis.2015.09.004 